\title{
Satisfaction level of Physical Therapy Services among Hospitals of Lahore
}

\section{Samiah Sarwar ${ }^{1}$, Farrukh Murtaza ${ }^{2}$, Salwa Atta ${ }^{3}$, Almas Shabbir $^{4}$, Iqra Tul Hussain ${ }^{5}$}

\author{
${ }^{1}$ Physical Therapist, CMH Hospital, Sialkot, Pakistan \\ 2 Lecturer, University of Lahore, Lahore \\ ${ }^{3}$ Senior Lecturer, Lahore College of Physical Therapy, LMDC, Lahore \\ ${ }^{4}$ Lecturer, University of Lahore, Lahore \\ ${ }^{5}$ Lecturer, Sialkot Medical College, Department of Physical Therapy, Sialkot, Pakistan
}

Author's Contribution

${ }_{1,3}$ Conception and design, ${ }^{2}$ Collection and assembly of data, ${ }^{1,4}$ Analysis and interpretation of the data, ${ }^{3,5} \mathrm{Critical}$ revision of the article for important intellectual content, 1Statistical expertise, Final approval and guarantor of the article.

Article Info.

Received: Dec 30, 2020

Acceptance: Nov 3, 2021

Conflict of Interest: None

Funding Sources: None

Address of Correspondence

Salwa Atta

Email ld: salwaatta4@gmail.com

ORIC Id: 0000-0001-9945-6830

Cite this article as Sarwar S, Murtaza F, Atta S, Shabbir A, Hussain IT. Satisfaction level of Physical Therapy Services among Hospitals of Lahore. JRCRS. 2021; 9(2):43-47.

DOI: $10.53389 / J R C R S .2021090201$

\section{A B S T R A C T}

Background: Physical therapy is a rehabilitation based treatment method which nonsurgically treats patient pains and help them accomplish their needs and goals. Patient satisfaction is assessed to evaluate the treatment standards and depends on multiple factors.

Objective: To determine the levels of satisfaction in patients visiting physiotherapy OPD of Public Hospitals in Lahore.

Methodology: This was a cross-sectional study including 405 patients of age 18-55 years from Public Hospitals in Lahore including patients who had been attending more than 5-6 physical therapy sessions from public Hospitals of Lahore. Patients with any cognitive dysfunctions and those who could no comprehend and provide the correct responses were excluded from the study. The outcome measure was Patient satisfaction and was assessed by using the Medrisk Instrument for Patient Satisfaction.

Results: Amongst 405 questionnaires that were given out as handouts, 377 fulfilled the criteria and thus were analyzed. Out of 377 patients who consented for the study 248 had low levels, 103 had moderate and only 26 patients had higher levels of satisfaction according to Medrisk Instrument for patient satisfaction. Chi-square test indicated a significance of 0.00 i.e. highly significant.

Conclusion: Patients were least satisfied with the quality of care and services provided by the therapist at Public Hospitals in Lahore. Patients who had lower levels indicated lesser time spent with their therapist and lack of enough information from the therapist to be the causative factors for their satisfaction levels.

Keywords: Patient Satisfaction, Physiotherapy.

\section{Introduction}

Physical therapy is known to be a rehabilitation based profession which has a major role in maintenance of health and prevention of impairments of both musculoskeletal and neuromuscular nature. ${ }^{1}$ It may be based on direct or indirect access of patients for physical therapy and the session usually comprises of examination, evaluation, diagnosis, prognosis and plan of care. ${ }^{2}$ There has been a change in paradigm after the evidence based practice has prevailed and now demonstrates a move towards care which is patient centered and now known to be dominant paradigm in health service. ${ }^{3}$ One important component of quality health care is patient satisfaction. There has been very little research on patient satisfaction in physiotherapy as compared to those of other clinical fields. Few studies have explored patient attitudes along with patient satisfaction from physical therapy services. ${ }^{4}$ These surveys are of prime importance for health service delivery and professionals. Such surveys can be used to measure the success in information deliverance and predict attendance and compliance to treatment of patients which keeps much importance in the management of problems..$^{5-8}$ According to the literature available, there are mixed perceptions about patient satisfaction questionnaires and about in what way they reflect 
the quality of services being provided. ${ }^{9}$ According to some surveys and research conducted internationally. The Chartered society of Physiotherapy (UK) have now included patient satisfaction questionnaires in their Core Standards of Practice and have not provided any valid outcome to measure satisfaction from physical therapy treatment. The majority of such literature is UK based and the standards of practice there cannot be matched to that in Pakistan and thus make comparisons difficult. ${ }^{10}$ Moreover, other tools used to assess patient satisfaction have unclear properties i.e. validity and reliability..$^{11}$ Although, none of the methodologies for measuring patient satisfaction is recommended over another, studies mostly use self-report questionnaires that are known to be less expensive and less time consuming. ${ }^{12-14}$

Satisfaction of patients is a very essential component when considering general health as well as psychological status of patients. Patient satisfaction has always helped patients get treated at a faster rate than those who are not satisfied with their therapists and doctors. Thus, in order to obtain timely treatment of the patients, one should encourage all those factors which appreciate patient satisfaction and remove all those barriers which may reduce or affect satisfaction of patients in a negative way.

In order to study the trends of satisfaction of patients from physical therapy services provided to them, different studies have been documented in different countries. Researches based on patient satisfaction report higher levels of contentment from health services delivery across the country. For some unknown components of care, this may reflect valid patient views but the results of such studies cannot be generalized for all departments involved in health care. This study was conducted in physical therapy departments of different government Hospitals of Lahore.

It was conducted to determine that patients coming to the physical therapy OPD's were satisfied with the treatment provided, location of facility, prognosis and the quality of physiotherapy treatment provided by the therapists or not.

\section{Methodology}

The sample size was calculated through Epi Info Software keeping the confidence interval set at $95 \%$, design effect-1, cluster 1 and margin of error at 5 i.e. $0.5 \%$. Therefore $n$ was calculated to be 369.405 questionnaires were printed and distributed among patients recruited through convenient sampling technique. Data was collected from patients who received physical therapy from respective departments in Public Hospitals after taking their consent. Ethical approval was taken from Board of Advance sciences and research. A total of 377 patients fulfilled the inclusion criteria and were inquired about the quality of physiotherapy treatment they receive in Public Hospitals of Lahore. Study participants: Data was obtained from the Physical Therapy OPD's from Public Hospitals in Lahore. The hospitals which were included in the study had Physical Therapy departments operational from more than 5 years and had at least 2 senior and 2 junior physical therapists under the supervision of a Head of Department. The list of Public Hospitals was extracted from the E- record.

LGH; Lahore General Hospital, Mayo Hospital, Lahore , Jinnah Hospital, Lahore, The Children's Hospital, Lady Willingdon Hospital, Nawaz Sharif Social Security Hospital, Multan Road, Punjab Institute of Cardiology, Punjab Social Security Hospital, Services Hospital, Shaikh Zayed Hospital, Sir Ganga Ram Hospital, Wapda Hospital.

Patients of age 18-55 years and those who have received more than 5-6 visits from the same department were included in the study. Patients who had any congenital or cognitive dysfunction were excluded from the study. Patients who did not adhere and did not offer their consent were also excluded.

Instruments and Procedure: The data collection tool was the Medrisk Instrument for patient satisfaction in Physical Therapy. Validity and reliability were correlated with the 2 global measures, ranging from $r=0.68$ to $r=0.80$. The standard error of measure was 0.20 for the internal factor and 0.17 for the external factor. The statistical analysis was conducted using SPSS version 22.

\section{Results}

The mean age of 377 patients who were included in the study was found to be $47.96 \pm 9.537$ years. Majority of the patients who visited the physiotherapy OPD were middle aged adults. Out of 377 patients, 145 i.e. $38.46 \%$ were found to be males whereas 232 i.e. $61.54 \%$ were females. Reason of attending physiotherapy sessions were shown below. (Table no I) Patient Satisfaction Level was measured with medrisk instrument. (Table no II \& II)

\begin{tabular}{l|l}
\hline \multicolumn{2}{l}{ Table I: Reason of taking Physiotherapy sessions } \\
\hline Condition Types & Frequency (\%) \\
\hline Neurological conditions & $151(40.1 \%)$ \\
\hline Orthopedic Conditions & $129(34.2 \%)$ \\
\hline Musculoskeletal Conditions & $70(18.6 \%)$ \\
\hline Others & $27(7.2 \%)$ \\
\hline Total & $377(100 \%)$ \\
\hline
\end{tabular}

Patients were inquired about the number of sessions they had taken for their condition. Out of 377 patients, 12 
patients i.e. $3.18 \%$ had taken 4 sessions, 153 i.e. $40.58 \%$ had taken 5 sessions, 154 i.e. $40.85 \%$ had taken 6 sessions, 19 i.e. $5.04 \%$ had taken 7 sessions 24 i.e. $6.37 \%$ had taken 8 sessions, 11 i.e. $2.92 \%$ attended 9 sessions, 1 i.e. $0.27 \%$ attended 10 sessions, 1 i.e. $0.27 \%$ attended 14 sessions, 1 i.e. $0.27 \%$ attended 15 sessions and 1 i.e. $0.27 \%$ attended 16 sessions.

Out of 377 patients who were included in the study, 162 i.e. $42.97 \%$ had taken their treatment by a single therapist, 123 i.e. $32.63 \%$ had taken sessions by two different therapists at the same centre, 68 i.e. $18.04 \%$ had taken sessions from two different therapist at different centres and 24 i.e. $6.37 \%$ had taken their sessions from more than two therapists.

A chi square test when applied revealed a significance of 0.00 i.e. highly significant which identified lower levels of satisfaction in patients who were taking physiotherapy sessions from Public Hospitals in comparison to those who took their sessions from Private Hospitals of Lahore.

\section{Discussion}

A number of studies consistently reported higher levels of satisfaction in patients who received physical therapy. ${ }^{14-19} \mathrm{~A}$ very high proportion of patients reported that they were completely satisfied with the physical therapy services they are provided. High patient satisfaction levels were reported from diverse clinical settings at distant geographical regions which included North America, United Kingdom, Ireland and North Europe. ${ }^{23}$ These studies indicated that patients who received musculoskeletal physical therapy received high quality care for Physical Therapists. Studies also suggested that specific patient characteristics were also associated with higher satisfaction levels in patients i.e. patients with acute condition reported of higher satisfaction than those with chronic conditions. ${ }^{24}$

Patients who had their symptoms at acute stage of severity were found to be positive and more concerned about the outcomes of their treatment sessions having higher expectations as compared to those who had chronic conditions and were less satisfied with their physical therapy sessions because of the effects of therapy on chronic impairments. ${ }^{25} \mathrm{~A}$ theoretical model by Hills and Kitchen explored the evidence that patients of older ages had higher satisfaction scores for physical therapy as compared to those who are younger. Similar trends were also reported from patients receiving inpatient and outpatient health services in United Kingdom. ${ }^{26}$ Another hypothesis suggests that older patients after experiencing chronic pain and mobility defects have a greater

\begin{tabular}{|c|c|c|c|c|c|}
\hline Statement & $\begin{array}{c}\text { Strongly } \\
\text { disagree } \mathrm{N}(\%)\end{array}$ & $\begin{array}{l}\text { Disagree } \\
\mathrm{N}(\%)\end{array}$ & $\begin{array}{c}\text { Neutral } \\
\mathrm{N}(\%)\end{array}$ & $\begin{array}{c}\text { Agree } \\
\mathrm{N}(\%)\end{array}$ & $\begin{array}{l}\text { Strongly agree } \\
\mathrm{N}(\%)\end{array}$ \\
\hline My Physical therapist is courteous & $0(0 \%)$ & $12(3.2 \%)$ & $79(21.0)$ & $117(31.0)$ & $169(44.8)$ \\
\hline The registration process is not appropriate & $9(2.4 \%)$ & $77(20.4 \%)$ & $96(25.5)$ & $120(31.8)$ & $75(19.9)$ \\
\hline The waiting area is comfortable & $50(13.3 \%)$ & $99(26.3 \%)$ & $96(25.5)$ & $99(26.3)$ & $33(8.8)$ \\
\hline $\begin{array}{l}\text { My therapist did not spend enough time with } \\
\text { me }\end{array}$ & $51(13.5 \%)$ & $138(36.6 \%)$ & $64(17.0)$ & $67(17.8)$ & $57(15.1)$ \\
\hline $\begin{array}{l}\text { My therapist explains the treatment I received } \\
\text { thoroughly }\end{array}$ & $0(0 \%)$ & $99(26.3 \%)$ & $79(21.0)$ & $71(18.8)$ & $107(28.4)$ \\
\hline My therapist treats me respectfully & $0(0 \%)$ & $0(0 \%)$ & 138(36.6) & 118(31.3) & 121(32.1) \\
\hline My therapist listens to my concerns & $3(0.8 \%)$ & $41(10.9)$ & $95(25.2)$ & $103(27.3)$ & $135(35.8)$ \\
\hline The location of the facility is convenient for me & $27(7.2 \%)$ & $56(14.9)$ & $83(22)$ & $116(30.8)$ & $95(25.2)$ \\
\hline $\begin{array}{l}\text { My therapist advices me to avoid future } \\
\text { problems }\end{array}$ & $0(0 \%)$ & $0(0 \%)$ & 121(32.1) & 118(31.3) & 138(36.6) \\
\hline My therapist gives me a home plan & $77(20.4 \%)$ & $133(35.3)$ & $47(12.5)$ & $40(10.6)$ & $80(21.2)$ \\
\hline $\begin{array}{l}\text { I am completely satisfied with the services I } \\
\text { receive }\end{array}$ & $0(0 \%)$ & $24(6.4)$ & 151(40.1) & 118(31.3) & $84(22.3)$ \\
\hline The bills I pay are appropriate & $6(1.6 \%)$ & 154(40.8) & 144(38.2) & $68(18.0)$ & $5(1.3)$ \\
\hline
\end{tabular}

\begin{tabular}{lcccc}
\hline Table III: Patient satisfaction level & & \\
\cline { 2 - 4 } & \multicolumn{3}{c}{ Levels of satisfaction } & Total \\
& $\begin{array}{l}\text { Low } \\
\text { level }\end{array}$ & $\begin{array}{c}\text { Moderate } \\
\text { level }\end{array}$ & $\begin{array}{c}\text { High } \\
\text { level }\end{array}$ & \\
\hline $\begin{array}{l}\text { Number of } \\
\text { patients }\end{array}$ & 248 & 103 & 26 & 377 \\
\hline
\end{tabular}

need of assistance which is provided by physical therapy thus effectively managing their problems and making them more independent. ${ }^{27}$ It is also reported that older patients have lower expectations and lower demands than younger. ${ }^{28}$ This is why they are more satisfied with the physical therapy care.

There is also a notable difference reported for satisfaction scores of females \& males. Females are usually 
less satisfied with their treatment sessions than males. ${ }^{29} \mathrm{An}$ explanation to this may be different satisfaction determinants which include communication in case of females whereas therapist and outcome in case of males. Another factor which was found to be a major determinant of levels of patient satisfaction was the attributes of therapist. ${ }^{30}$ The therapist's knowledge, skill, professionalism, practical experience and effective communication skills were the factors known to influence patient satisfaction. Patients reported some important aspects of communication which included that the therapist should provide a helpful explanation about the condition of patient, provision of prognostic information and the ability to inform about patient's role in the process of treatment. ${ }^{31}$ The professionalism of therapist should allow their patients to have a realization that they are respectful for the therapist and are always listened to. These factors are known to be amongst the major determinants of patient satisfaction. ${ }^{32}$ Another determinant is the process of care provided by the therapist to the patient. The key variables that were found to result in higher levels of satisfaction were an adequate frequency and duration of treatment, a regular follow up, treatment mode, patient knowledge about continuity and discontinuity of care along with the intervening of their patients in shared decision making. ${ }^{33}$

Low levels of satisfaction were reported from patients who felt that the therapist was in a rush throughout their appointment and did not give adequate time to the patient and that they were not carefully re-evaluated. ${ }^{14}$ Another study on patient satisfaction reported importance of longitudinal continuity in patient care i.e. the course of treatment should be followed by a single therapist to improve patient satisfaction levels and that patients who received therapy from multiple therapists were 3 times lesser satisfied. ${ }^{35}$ The mode of treatment also influences patient satisfaction level i.e. patients having back pain were reported to be more satisfied with exercise based treatment than with passive treatment modalities.

A study conducted in Northern Europe found out that a proportion of patients wanted lesser involvement in the decision making process as they considered that the therapist is an expert and shall assess each of the patients desire accordingly. Multiple studies reported a higher satisfaction from physical therapy care in patients with back pain than medical care ${ }^{16} \mathrm{~A}$ reason of this was that there is a longer consultancy period in physical therapy and a more detailed up to date information can be given to the patient compared with the general medical practice.

The major limitation of the study is that it does not have a representative of a wider population of patients receiving physical therapy care that affects the accuracy and generalizability of findings. Future researches should work on improving the response rate thus reducing the non-response.

\section{Conclusion}

Patients who visited public Hospitals for their Physiotherapy sessions were less satisfied with the quality of services and care provided. The causative factors behind lower satisfaction levels were found to be lesser time spent by the therapist with the patient and lack of explanation of treatment and problem by the therapist to the patient.

Recommendation: Future researches should include random sampling and a larger sample size in order to obtain a feedback from patients to improve the service standards. Moreover a comparative study should be conducted to compare satisfaction levels with those who visit private hospitals.

\section{References}

1. Hawker GA, Conner-Spady BL, Bohm E, Dunbar MJ, Jones CA, Ravi B, Noseworthy T, Dick D, Powell J, Paul P, Marshall DA. Patients' Preoperative Expectations of Total Knee Arthroplasty and Satisfaction With Outcomes at One Year: A Prospective Cohort Study. Arthritis \& Rheumatology. 2021 Feb;73(2):223-31.

2. Butler RJ, Johnson WG. Satisfaction with low back pain care. Spine J. 200

3. Nakhostin Ansari N, Naghdi S, Alaei P, Komesh S, Emami Razavi SZ, Azadvari M, Moghimi E, Beattie P. The MedRisk instrument for measuring patient satisfaction with physical therapy care: A validation of the Persian-language version. Physiotherapy theory and practice. 2020 Apr 27:10.

4. Gutiérrez-Sánchez D, Pérez-Cruzado D, Cuesta-Vargas Al. Instruments for measuring satisfaction with physical therapy care: A systematic review. Physical Therapy. 2020 Aug 31;100(9):1690-700.

5. Law B, Driediger M, Hall C et al. Imagery use, perceived pain, limb functioning and satisfaction in athletic injury rehabilitation. New Zealand Journal of Physiotherapy. 2006

6. McKinnon AL. Client satisfaction with physical therapy services: Does age make a difference?. Physical \& Occupational Therapy in Geriatrics. 2001 Jan 1;19(2):2337.

7. Layzell M. Back pain management: a patient satisfaction study of services. Br J Nurs. 2001

8. Stephens B, Gross DP. The influence of a continuum of care model on the rehabilitation of compensation claimants with soft tissue disorders. Spine. 2007

9. Babur, Muhammad, Malik, Junaid M. Patient's satisfaction in physical therapy OPD of Al Nafees Hospital Islmabad.2007 
10. Fedorenko S, Vitomskyi V, Lazarieva O, Kashuba V, Andrieieva O, Vitomska M, Vladimir $\mathrm{P}$, et al. Influence Specificities of the Type of Attitude towards a Disease on Physical Therapy Satisfaction Among the Orthopedic Profile Patients and the Possibilities of Attitude Improvement. Journal of Physical Education and Sport. 2020 Mar 1;20(2):896-904.

11. MacDonald CA, Cox PD, Bartlett DJ. Productivity and client satisfaction: a comparison between physical therapists and student-therapist pairs. Physiother Can. 2002.

12. Wagner D, Bear M. Patient satisfaction with nursing care: a concept analysis within a nursing framework. Journal of advanced nursing. 2009 Mar;65(3):692-701.

13. Casserley-Feeney SN, Phelan M, Duffy F, Roush S, Cairns MC, Hurley DA. Patient satisfaction with private physiotherapy for musculoskeletal pain. BMC musculoskeletal disorders. $2008 \mathrm{Dec} ; 9(1): 1-3$.

14. Beattie PF, Dowda $M$, Turner $C$, et al. Longitudinal continuity of care is associated with high patient satisfaction with physical therapy. Phys Ther. 2005

15. Cooper KS, Blair, H. Hancock, E. Patient centredness in physiotherapy from the perspective of the low back pain patient. Physiotherapy. 2008

16. De Paula DA, Piatti NC, Costa LM, Chiavegato LD. Satisfaction levels with physical therapy in hospitalized patients. Brazilian journal of physical therapy. 2020 Mar 1;24(2):118-23.

17. Hills $R$, Kitchen $S$. Satisfaction with outpatient physiotherapy: a survey comparing the views of patients with acute and chronic musculoskeletal conditions. Physiotherapy theory and practice. 2007 Jan 1;23(1):2136.

18. Beattie PF, Turner C, Dowda M, et al. The MedRisk Instrument for Measuring Patient Satisfaction With Physical Therapy Care: a psychometric analysis. J Orthop Sports Phys Ther. 2005;

19. Galea VP, Rojanasopondist P, Connelly JW, Bragdon CR, Huddleston III JI, Ingelsrud LH, Malchau H, Troelsen A. Changes in patient satisfaction following total joint arthroplasty. The Journal of arthroplasty. 2020 Jan 1;35(1):32-8.

20. May SJ. Patient satisfaction with management of back pain main. Physiotherapy. 2001 Jan 1;87(1):4-20.

21. Hills $R$, Kitchen $S$. Satisfaction with outpatient physiotherapy: focus groups to explore the views of patients with acute and chronic musculoskeletal conditions. Physiother Theory Pract. 2007; 23(1):1-20

22. Dawes J. Do data characteristics change according to the number of scale points used? Int J Market Res. 2008; 61104

23. Galea VP, Rojanasopondist $P$, Connelly JW, Bragdon CR, Huddleston III JI, Ingelsrud LH, Malchau H, Troelsen A. Changes in patient satisfaction following total joint arthroplasty. The Journal of arthroplasty. 2020 Jan 1;35(1):32-8.

24. Australia's Health 2008: The Eleventh Biennial Health Report of the Australian Institute of Health and Welfare. 11th ed. Canberra, Australia: Australian Institute of Health and Welfare; 2008.

25. Kahlenberg CA, Nwachukwu BU, McLawhorn AS, Cross $\mathrm{MB}$, Cornell CN, Padgett DE. Patient satisfaction after total knee replacement: a systematic review. HSS Journal®. 2018 Jul;14(2):192-201.

26. Beattie PF, Nelson RM, Lis A. Spanishlanguage version of the MedRisk Instrument for Measuring Patient Satisfaction With Physical Therapy Care (MRPS): preliminary validation. Phys Ther. 2007

27. Beattie PF, Nelson RM. Preserving the quality of the patient-therapist relationship: an important consideration for valuecentered physical therapy care. J Orthop Sports Phys Ther. 2008;38(2):34-35.

28. Goldstein MS, Elliott SD, Guccione AA. The development of an instrument to measure satisfaction with physical therapy. Phys Ther. 2000;80(9):853-63

29. Hirsh AT, Atchison JW, Berger JJ, Waxenberg LB, Lafayette-Lucey A, Bulcourf BB, Robinson ME. Patient satisfaction with treatment for chronic pain: predictors and relationship to compliance. The Clinical journal of pain. 2005 Jul 1;21(4):302-10.

30. George SZ, Hirsh AT. Distinguishing patient satisfaction with treatment delivery from treatment effect: a preliminary investigation of patient satisfaction with symptoms after physical therapy treatment of low back pain. Archives of physical medicine and rehabilitation. 2005 Jul 1;86(7):1338-44.

31. Hills R, Kitchen S. Development of a model of patient satisfaction with physiotherapy. Physiother Theory Pract. $2007 ; 23(5): 243-54$

32. Lebow J. Reserach assessing consumer satisfaction with mental health treatment: a review of findings. Evaluation and Program Planning.1983; 6(3-4):211-36.

\section{Copyright Policy}

All Articles are made available under a Creative Commons "Attribution-NonCommercial 4.0 International" license. (https://creativecommons.org/licenses/by-nc/4.0/). Copyrights on any open access article published by Journal Riphah college of Rehabilitation Science (JRCRS) are retained by the author(s). Authors retain the rights of free downloading/unlimited e-print of full text and sharing/disseminating the article without any restriction, by any means; provided the article is correctly cited. JRCRS does not allow commercial use of the articles published. All articles published represent the view of the authors and do not reflect the official policy of IRCRS 